\title{
Critical Overview of Adolescent Suicides in India; A Public Health Concern.
}

\author{
Ashwin Mathew ${ }^{1}$, Suja M.K. ${ }^{2}$, V. Priya ${ }^{3}$ \\ ${ }^{1}$ Ph.D. Scholar, ${ }^{2}$ Associate Professor, ${ }^{3}$ Assistant Professor, Department of Social Work, \\ Amrita School of Engineering, Coimbatore, Amrita Vishwa Vidyapeetham, India
}

\begin{abstract}
Suicide is the second most leading cause of death among the 15-29 age group (adolescent). The World Health Organization statistics indicate that 8,00,000 people suicide annually. The National Crime Records Bureau records indicates that suicidal deaths in 2014 is $15.8 \%$ more than $2004,17 \%$ of the suicides worldwide happens in India. Suicides is a contingency that affects the victim's family community and nation at large and has a long lasting effect on the people left behind. The adolescents often don't get help when needed which leads to suicides. Sustainable Development Goals 3 intents to promote healthy lives and promote wellbeing for all.
\end{abstract}

Aim: To understand; 1) the percentage increase of suicide in India, difference between male and female suicides, 2) identify states with maximum number of suicides, 3 ) identify states with maximum number of student suicides, 4) Major Causes for suicide among adolescent male, female and trans gender and to study 5) Major means adopted for suicides in India, 6) Understand the significance promoting wellness addressing adolescent suicides.

Results: there is significant increase in number of suicides form 2013 to 2016 and it affects the nation's economy. The states with maximum number of adolescent suicides are 1) Maharastra, 2) Tamil Nadu, 3) West Bengal, 4) Madhya Pradesh and 5) Karnataka. The major Causes for suicides among adolescents male, female and trans gender were identified. The most common means adopted for suicide among adolescents have been identified and listed.

Conclusion: The adolescent and student suicides in the nation are increasing rapidly causing serious economic burden to the nation. Hence a comprehensive suicide prevention plan must be developed, the policy should individually target the states with highest number of adolescent and student suicides, access to the most prominent means of suicides must be limited. A national suicide prevention help line and community based access points could be created to provide mental health first aid to the vulnerable adolescents and students.

Keywords: Adolescent Suicides, Student Suicides, Economic Burden of Suicides, Suicide Prevention Policy, Adolescent Wellness, Adolescent Suicides in India, Suicides in Indian States.

\section{Introduction}

\section{Corresponding Author:}

\section{Ashwin Mathew}

Ph.D. Scholar, Department of Social Work, Amrita School of Engineering, Amrita Vishwa Vidyapeetham, Amritanagar, Ettimadai, Coimbatore, Tamil Nadu 641112, India

Phone No.: 7012291028

e-mail: ashwinmathew.alberts@gmail.com
WHO recognizes suicides as a public health priority and plans to increase the awareness regarding suicide and suicide attempts and intents to make suicide prevention as global public health priority. The Sustainable Development Goals (SDGs) 3 is to ensure healthy lives and promote wellbeing for all. ${ }^{(1)}$ The WHO statistics indicate that $8,00,000$ people attempt suicide and many more attempt suicide suicides. Suicide is the 
second most leading reason cause of death among the age group 15-29 age group (adolescent), 79\% of the suicide worldwide happens in lower middle income country and hence India is at greater risk. ${ }^{(2)}$ The National Crime Records Bureau reports indicate that the suicides rate has increased $15.8 \%$ from 2004 to $2014^{(3)}$, this significantly impairs the nation's development the government and parents of the adolescents spend considerable amount of money in their upbringing.

Suicidemental health problems and depression has high correlation especially in developed nations. Suicide occurs impulsively at crisis situations as the victim is not able to deal with the life stress in situations such as; financial problems, relationship issues and chronic diseases. The most significant factor for suicide is a previous suicide attempt. The crucial aspect in suicide risk reduction is to identify the Causes for suicide and address them and to limit access to the means of suicides. ${ }^{(4)}$

Research studies indicate that; indicate that suicide victims and inpatients showed similarly high rates of affective disorders. The suicide victims with family history of affective disorders and suicidal tenancies are more vulnerable to suicide. Four significant risk factors identified are 1) Bipolar Disorders, 2) Affective disorders with comorbidity, 3) Lack of previous mental health treatment and 4) availability of fire arms which accounted for $81.9 \%$ of cases. ${ }^{(4)}$ Prevention programs including Peer Educators (PEs) have been found useful in helping young people in school especially the adolescents going through heavy psychological burden. The results indicate that that the mindfulness and Support, Appreciate, Listen, Team (SALT) using Peer Educators (PE) have enhanced the PEs broad emotional intelligence and PEs expressed increased ownership of life, taking actionand seeking support when needed. Research studies also suggest that future research should be carried out in developing nations to understand the knowledge regarding suicides especially in the adolescent age group ${ }^{(5)}$. WHO further emphasizes that India develop a comprehensive suicide prevention plan and integrate it with the mental health act to contain the growing threat of adolescent suicides. ${ }^{(1)}$

\section{Method}

This study is based on the secondary data available from the official government websites. The adolescent suicides related data from 2013 to 2016 has been used in the study. The basic statistical analysis was done using Microsoft Excel 2013.

The rationale behind this study is to understand 1) National adolescent suicide rate and difference between male and female suicides, 2) States with highest number of suicides, 3) States with highest number of student suicides and rate of student suicides, 4) Major Causes for adolescent suicides 5) Major means adopted by adolescent suicides and 6) Understand the significance promoting wellness addressing adolescent suicides. The researcher would also attempt to identify future research areas and try to lay down a comprehensive suicide policy guidelines keeping in mind the recommendations of WHO and UNICEF and relevant research studies. ${ }^{16}$

\section{Results}

1. Total Suicides among 15-29 Age Group (Adolescent) in India; Years 2013, 2014 \& 2015. ${ }^{(6),(7),(8),(9)}$ : The number of suicide in 2013 is 46,368 , in 2014 it has raised to 54,100 . The percentage increase of suicides form 2013 to 2014 is a whopping $16.675 \%$ which is a matter of concern when we compare this data with the National Crime Records Bureau report stating that "suicidal deaths of 2014 is $15.4 \%$ higher than that of 2004", we can understand the rapid increase in adolescent suicide in India which is a public health concern. The increasing number of suicides is a threat to the nations GDP, it's estimated that death of one adolescent between the 15-29 years cost approximately 70 lakhs. The economic loss in 2014 alone would account to 70 lakhs $\times 54100$ adolescent suicides which equals to 378.7 billion rupee, this significantly affect the nation's economic progress and the public health initiatives.

Male and Female Suicides among the Adolescent Age Group in India; Years 2013, 2014 And

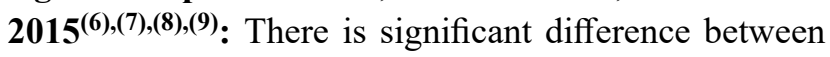
male and female suicides. The number of male suicides is significantly higher than that of the female suicides. The difference between male and female suicide in 2013 is 7,064 suicides, in 2014 the difference between male and female suicides is 9,950 suicides, and in 2015 the difference between male and female suicides is 9,435 suicides.

2. Suicide Rate amongst Adolecens in India 20132015 ${ }^{(6),(7),(8),(9)}$; States with Highest Number of Suicides: The states with highest number of suicides 
in 2013, 2014 \& 2015 are 1) Maharashtra, 2) Tamil Nadu, 3) West Bengal, 4) Madhya Pradesh, 5) Karnataka and 6)Andra Pradesh. Specific strategies must be formed to address suicides in these states as they contribute to the majority of the adolescent suicides in India.

3. Total Number of Student Suicides in India 20132016 $^{(10),(11),(12),(13)}$; States with Highest Number of Suicides: The states with maximum number of student suicides in India in the years 2013, 2014, 2015 and 2016 are; 1) Maharashtra, 2) Tamil Nadu, 3) West Bengal, 4) Madhya Pradesh, 5) Karnataka,6) Chhattisgarh, 7) Andra Pradesh.

The percentage increase in student suicide from 2013 to 2016 is an alarming $18.31 \%$. The government and parents spend a lot of time and effort in developing the career and character of a student and hence the rapid increase in student suicides significantly affects our nation's developmental gains.

\section{Causes for Suicide amongst Adolescent Age Group in India 2013 \& 2015; Male, Female \& Transgender ${ }^{(16)(17)}$}

Male: Figure No. 1, Causesfor Suicide amongst Adolescent Age Group in India 2013 \& 2015; Male (Suicide rate in percentage). ${ }^{(14)(15)}$

The most common Causesfor suicide among male in 2014 and 2015 are: 1) Other Causes, 2) Other Family Problems, 3) Causes not known, 4) Illnesses, 5) other prolonged illnesses, 6) love affairs, 7) Insanity/Mental Illnesses, 8) Failure in examination, 9) Marriage related issues, 10) Unemployment, 11) Drug Abuse/Addiction

Female: The Figure no. 2, Causesfor Suicide amongst Adolescent Age Group In India 2013 \& 2015; Female Illustrates that:

The mostcommon Causesfor death among adolescent female in India in 2014 and 2015 are; 1) Other Family problems, 2) Other Causes, 3) Marriage related issues, 4) Illnesses, 5) Causes not known, 6) Other Prolonged Illness, 7)Love affairs, 8) Dowry Related Issues, 9) Insanity/Mental Illness, 10) Examination Failures.

Trasgender: The Figure No. 3, Causesfor Suicide amongst Adolescent Age Group in India 2013 \& 2015; Transgender illustrates that:-

The most common Causesfor adolescent transgender suicides in 2014 and 2015 are; 1) Other Causes, 2)
Illnesses, 3) Other Prolonged illness, 4) Suspected/ illicit relation, 5) Professional/Career Problem, 6) Other family problem, 7) Insanity/Mental illnesses:-, 8) Drug Abuse Addiction, 9) Causes not known.

\section{Means of Suicide Adopted by Adolescent Age Group in India; Male, Female and Transgender in 2013 and 2015. ${ }^{(14)(15)}$ :}

Male: The Figure No. 4, Means of Suicide Adopted By Adolescent Age Group in India 2013 \& 2015; Male illustrates that:-

The most common means adopted by adolescent male in 2013 and 2015 in India are; 1) Hanging, 2) Poisoning, 3) consumption of insecticides, 4) fire/selfimmobilization, 5) consumption of other poison, 6) other means, 7) drowning, 8) coming under running trains, 9) jumping, 10)overdose of sleeping pills.

Female: The Figure No. 5, Means of Suicide Adopted By Adolescent Age Group in India 2013 \& 2015; Female illustrates that:

The most common means adopted by women in the adolescent age group for suicide in the years 2013 and 2014 are 1) Hanging, 2) Poisoning, 3) consumption of other poison, 4) fire self-immobilization, 5) consumption of other poison, 6) other means 7) drowning, 8) coming under running vehicles/trains, 9) Jumping and 10) over dose of sleeping pills.

Transgender: The Figure No. 6, Means of Suicide Adopted By Adolescent Age Group in India 2015; Transgender illustrates that :-

The most common Causes for suicide among transgender suicides in India are; 1) by fire/selfimmobilization, 2) by hanging, 3) Jumping and 4) jumping of moving trains/vehicles.

\section{Discussions and Conclusions}

The percentage increase in adolescent suicide in India from 2013 to 2014 is $16.67 \%$ is higher that the records published by the National Crime Records Bureau 15.4\% in increase from 2004 to 2014. The economic loss caused by adolescent suicides in 2014 accounts to 378.7 billion rupees which seriously affects the nation's developmental gains. The priority should be to prevent male suicides which is significantly higher than that of female suicides in India. The government and NGO's must individually target the states with 
maximum number of suicides in 2013,2014 and 2015 1) Maharashtra, 2) Tamil Nadu, 3) West Bengal, 4) Madhya Pradesh, 5)Karnataka and 6) Andra Pradesh.

The percentage increase in student's suicide from 2013 to 2016 is $18.31 \%$ is alarming. The states with the maximum number of student suicides should be individually targeted and suicide prevention strategies involving student volunteers and teachers could be introduced in the educational institutions to address student suicides.

The best way to prevent adolescent suicides is to understand the Causes for suicides and to take appropriate measures to address them states the WHO, hence the suicide prevention policy could try and target people who are vulnerable to; other causes, other family problems, causes not known, love affairs, illnesses, other prolonged illnesses, insanity or mental illness, failure in exams, marriage related issues, dowry problems, drug abuse/addiction, unemployment, suspected/illicit relations and professional and career problems.

Preventing access to the means of suicide helps in reducing the number of suicides as per WHO guidelines and we suicide prevention policy could try and limit access to the most common means of adolescent suicides; Hanging, poisoning, consumption of insecticides, consumption of other poison, other means, drowning, coming under running vehicles/trains, jumping, jumping of moving vehicles, overdose of sleeping pills, fire/selfimmobilizing'

Further research must be done to understand - 1) high number of male suicides, 2) high number of student suicides, 3) high student and adolescent suicides in certain states, 4) the leading causes of adolescent suicide other family problems and other problems, 5) the actual number of transgender suicides in India.

The government should try and develop a suicide prevention policy considering the recommendations; 1) the states with highest number of adolescent and student suicides should be targeted individually, 2) student volunteers should be trained in educational institutions to give support to the students, 3 ) the adolescents who are vulnerable to common means of suicide should be assisted, 4) Access to the common means of suicide should be reduced 5) government should try and start a suicide prevention helpline, computer based and mobile based chat support to help adolescents 6) community based access points to give mental health first aid 7) Community mental health volunteers could be trained and employed in the PHC-SHC-CHC respectively. The primary focus should be to reduce the adolescent suicides and to foster their growth for the betterment of the nation.

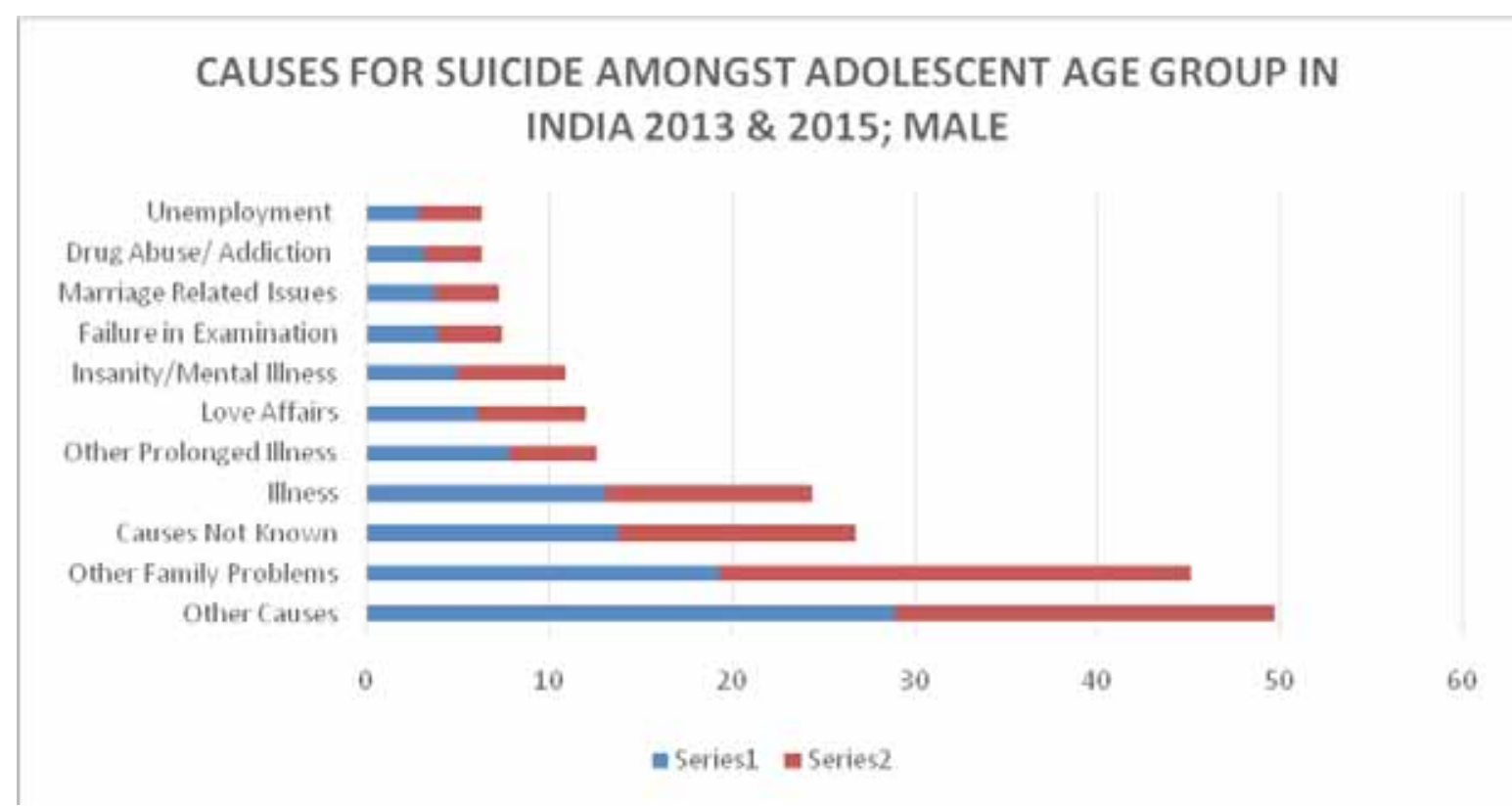

Figure No. 1, Causes for Suicide amongst Adolescent Age Group in India 2013 \& 2015; Male (Suicide rate in percentage) $)^{(16)(17)}$ 


\section{CAUSES FOR SUICIDE AMONGST ADOLESCENT AGE GROUP IN INDIA 2013 \& 2015; FEMALE}

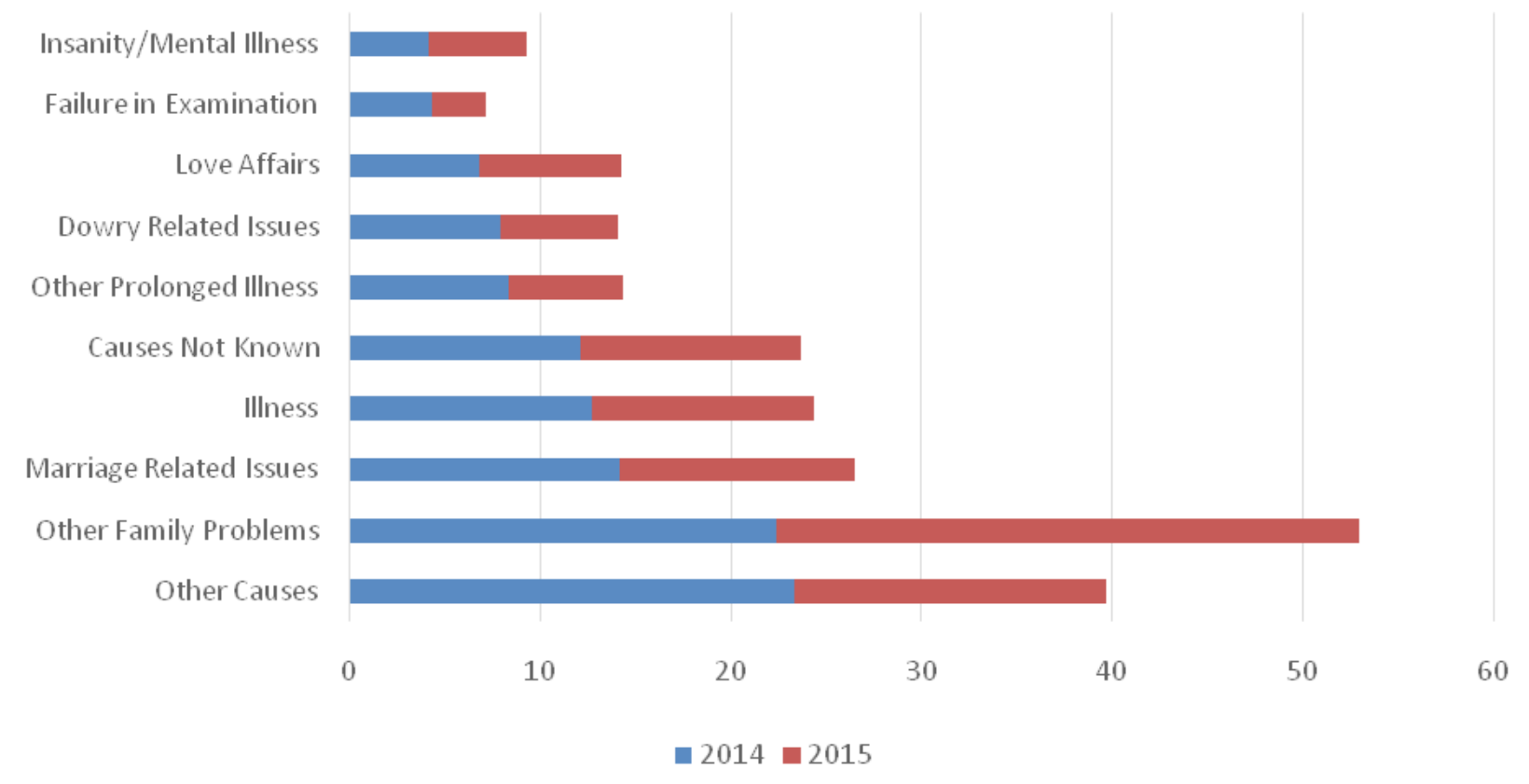

Figure No. 2, causes for Suicide amongst Adolescent Age Group in India 2013 \& 2015; Female (Suicide rate in percentage) ${ }^{(16)(17)}$

\section{CAUSES FOR SUICIDE AMONGST ADOLESCENT AGE GROUP IN INDIA 2013 \& 2015; TRANSGENDER}

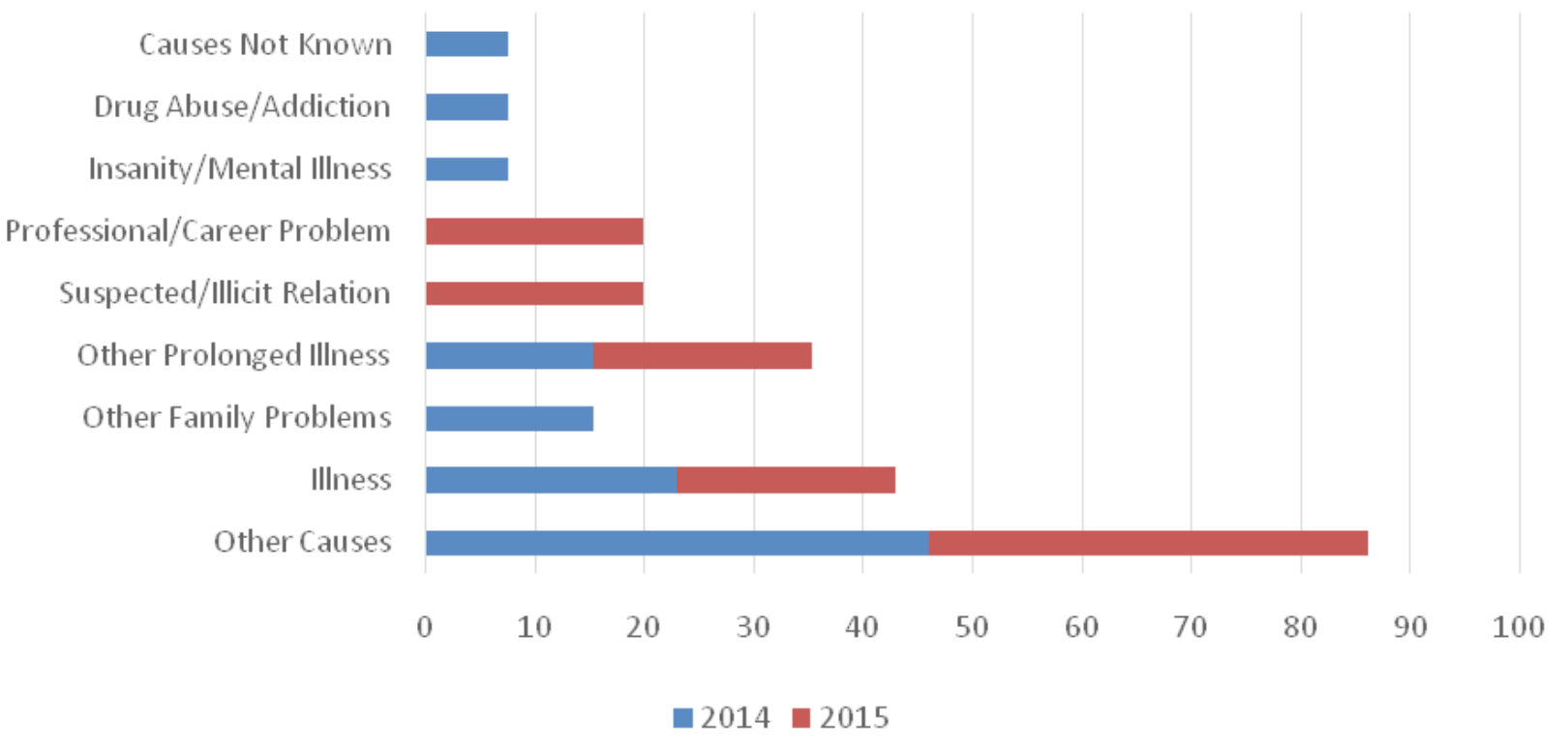

Figure No. 3, Causes for Suicide amongst Adolescent Age Group in India 2013 \& 2015; Transgender (Suicide rate in percentage) $^{(16)(17)}$ 


\section{MEANS OF SUICIDE ADOPTED BY ADOLESCENT AGE GROUP IN INDIA 2013 \& 2015; MALE}

by Jumping off Moving Trains/Vehicles Jumping Excessive Alcoholism Fire/Self Immolation Coming under running vehicles/ Trains Drowning Othermeans

(ii) Consumption of other Poison

(i) Consumption of Insecticides Poisoning Hanging

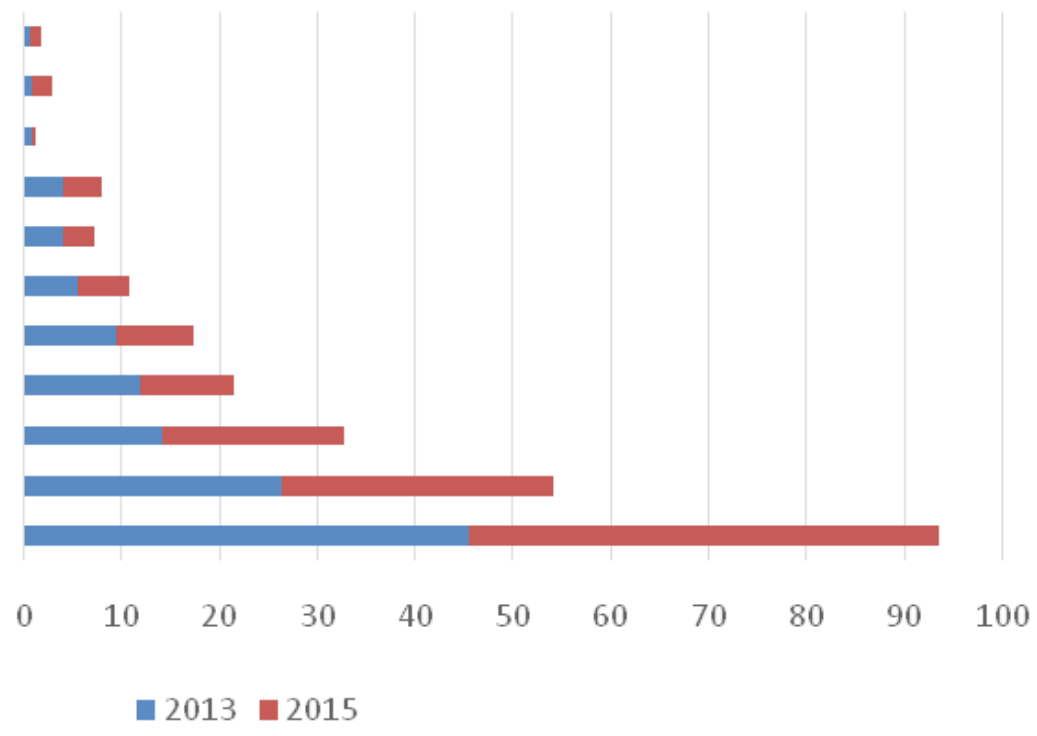

Figure No. 4, Means of Suicide Adopted By Adolescent Age Group in India 2013 \& 2015; Male (Suicide rate in percentage $)^{(14)(15)}$

\section{MEANS OF SUICIDE ADOPTED BY ADOLESCENT AGE GROUP IN INDIA 2013 \& 2015; FEMALE}

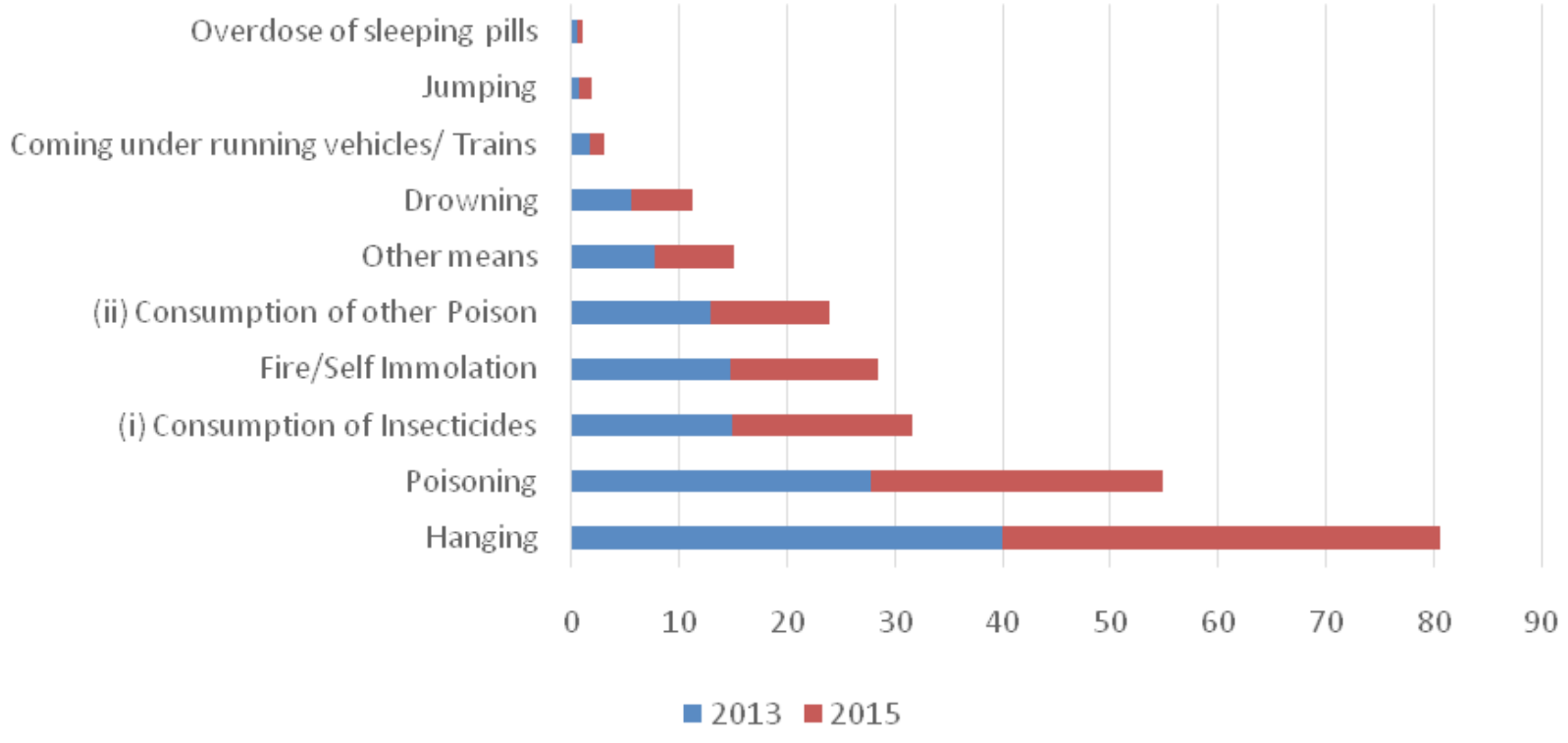

Figure No. 5, Means of Suicide Adopted By Adolescent Age Group in India 2013 \& 2015; Female (Suicide rate in percentage) $)^{(14)(15)}$ 


\section{MEANS OF SUICIDE ADOPTED BY ADOLESCENT AGE GROUP IN INDIA 2013 \& 2015; TRANSGENDER}

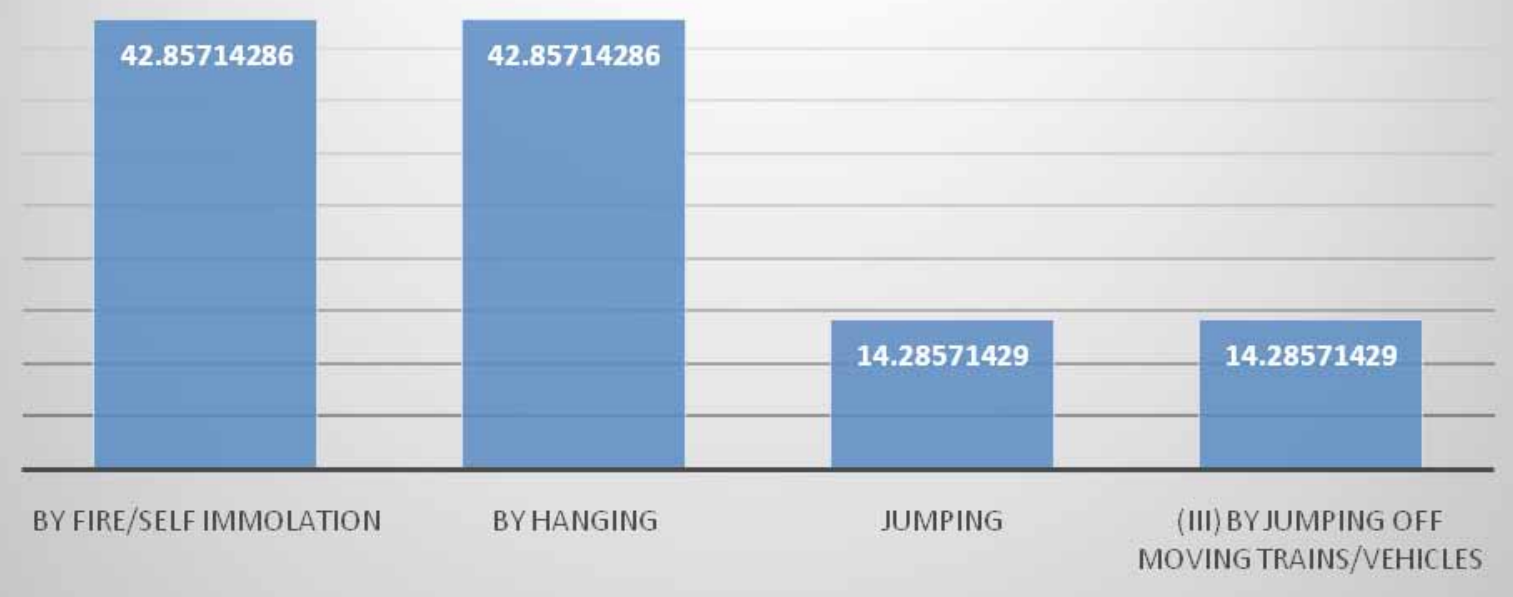

Figure No. 6, Means of Suicide Adopted By Adolescent Age Group in India \& 2015; Transgender. (Suicide rate in percentage) ${ }^{(14)}$

Ethical Clearance: Not Required

Conflict of Interest: Nil

Funding: Self

\section{References}

1. WHO. Suicide [Internet]. 2019. Available from: https:/www.who.int/news-room/fact-sheets/detail/ suicide

2. WHO. Mental Health - National suicide prevention stratergies, progress, examples and indicatiors [Internet]. 2018. Available from: https://apps.who.int/iris/bitstream/hand le/10665/279765/9789241515016-eng.pdf?ua=1

3. Kamalja KK, Khangar N V. A statistical study of suicidal behavior of Indians. Egypt J Forensic Sci [Internet]. 2017;7(1):12. Available from: https:// doi.org/10.1186/s41935-017-0007-9

4. Brent DA, Perper JA, Goldstein CE, Kolko DJ, Allan MJ, Allman CJ, et al. Risk Factors for Adolescent Suicide: A Comparison of Adolescent Suicide Victims With Suicidal Inpatients. Arch Gen Psychiatry. 1988;45(6):581-8.

5. Zachariah B, de Wit EE, Bahirat JD, BundersAelen JFG, Regeer BJ. What is in It for Them? Understanding the Impact of a 'Support, Appreciate,
Listen Team' (SALT)-Based Suicide Prevention Peer Education Program on Peer Educators. School Ment Health [Internet]. 2018;10(4):462-76. Available from: https://doi.org/10.1007/s12310018-9264-5

6. Ministry of Health \& Family Welfare G of I. Crime and Law - Suicides (State Wise) [Internet]. Vol. Part I, Indiastat. 2015. Available from: https:// www.indiastat.com/table/crime-and-law-data/6/ suicides/267/1151128/data.aspx

7. Ministry of Health \& Family Welfare G of I. Crime and Law - Suicides (State Wise) [Internet]. Vol. Part II, Indiastat. 2015. Available from: https:// www.indiastat.com/table/crime-and-law-data/6/ suicides/267/1151141/data.aspx

8. Implimentation, Ministry of Statistics and Programme G. Crime and Law - Suicides (State Wise) [Internet]. Indiastat. 2014. Available from: https://www.indiastat.com/table/crime-and-lawdata/6/distribution-of-suicidal-deaths-by-agegroup/477874/1004304/data.aspx

9. Ministry of Home Affairs G. Crime and Law Suicides (State Wise) [Internet]. Indiastat. 2013. p. Part I. Available from: https://www.indiastat. com/table/crime-and-law-data/6/distribution-ofsuicidal-deaths-by-age-group/477874/837734/ data.aspx 
10. 2451 LSUQN. Crime and Law - Suicides (Student) [Internet]. Indiastat. 2018. Available from: https:// www.indiastat.com/table/crime-and-law-data/6/ student-and-unemployed/478408/1200242/data. aspx

11. Ministry of Home Affairs G. Crime and LawSuicides (Student) [Internet]. Indiastat. 2015. Available from: https://www.indiastat.com/ table/crime-and-1aw-data/6/student-andunemployed/478408/1035300/data.aspx

12. GoI M of HA. Crime and Law - Suicides (Student) [Internet]. Indiastat. 2014. Available from: https:// www.indiastat.com/table/crime-and-law-data/6/ student-and-unemployed/478408/923076/data. aspx

13. GoI M of HA. Crime and Law - Suicides (Student) [Internet]. Indiastat. 2013. Available from: https:// www.indiastat.com/table/crime-and-law-data/6/ student-and-unemployed/478408/830807/data. aspx
14. GoI M of HA. Crime and Law - Suicides (Means) [Internet]. Indiastat. 2015. Available from: https:// www.indiastat.com/table/crime-and-law-data/6/ total-means-adopted/477873/1035523/data.aspx

15. GoI Mi of HA. Crime and Law-Suicides (Means) [Internet]. Indiastat. Available from: https://www. indiastat.com/table/crime-and-law-data/6/totalmeans-adopted/477873/837592/data.aspx

16. GoI M of HA. Crime and Law - Suicides (Causes) [Internet]. Indiastat. 2015. Available from: https:// www.indiastat.com/table/crime-and-law-data/6/ total-causes/477800/1034957/data.aspx

17. Ministry of Home Affairs G. Crime and Law-Suicides (Causes) [Internet]. Indiastat. 2014. p. Part I. Available from: https://www. indiastat.com/table/crime-and-law-data/6/totalcauses/477800/922253/data.aspx 